\title{
Comments and Deliberation on "the Fit and Departure between NBA Culture and the Mainstream American Culture"
}

\author{
Xiaofeng $\mathrm{Xu}$ \\ Department of Arts and Physical Education, Baoji Vocational Technology \\ College, Baoji, Shaanxi, 721006, China
}

\begin{abstract}
In the 6th issue of Journal of Guangzhou Institute of Physical Education in 2013, Mr. Zhang Feng published the article " the Fit and Departure between NBA Culture and the Mainstream American Culture ", where there is a question, Mr. Zhang Feng said that: 1) NBA culture is far from politics; 2) "hippie" culture is the culture parallel with the United States mainstream culture and it is the propellant to promote the global influence of NBA; 3) NBA culture is a relatively conservative culture. The NBA is in the political environment of the United States and can not get rid of the interference of political activities. The culture of "hippies" has been absorbed and reformed by mainstream culture. The spread of NBA is the main driving force of American mainstream culture. NBA culture absorbs foreign culture constantly, with the inclusive and innovative features.
\end{abstract}

Keywords: sports sociology; NBA culture; mainstream culture; hippie movement

\section{Introduction}

In the 6th issue of Journal of Guangzhou Institute of Physical Education in 2013, Mr. Zhang Feng published the article " the Fit and Departure between NBA Culture and the Mainstream American Culture", the full text is divided into four parts, with a brief overview and assumptions into the title; Second and third part of the NBA culture and American mainstream culture fit, departure from the empirical analysis of the final statement of the summary. The analysis of NBA culture and American mainstream culture is objective and true, and the 
conclusion is worthy of convincing. But we found that there are many points worthy of discussion in this article, mainly in the NBA culture and the mainstream culture of the United States deviate from the three empirical analysis: First, due to Rodman's visit to North Korea when the world political environment lack of understanding, NBA culture, the NBA, players, staff involved in political activities, the lack of data collection that "NBA culture is a different from the mainstream culture of the United States to the depoliticized culture"; Second, the "hippies" movement and "hippie" It is pointed out that "the culture of hippies is an important driving force to promote the spread of NBA". Thirdly, the author holds that "NBA culture belongs to the relative culture of the United States, Conservative culture, never copied to the rest of the world NBA culture, not to any place to instill NBA cultural values. We argue that although the empirical analysis of this paper is more scientific, there are some problems in the presupposition of the hypothesis, and it is inevitable that the conclusion will be made on the wrong assumption. In order to draw the conclusion that the NBA culture deviates from the American mainstream culture, this article analyzes the individual cases selectively and lacks some understanding of some cultural history. Based on this, we put forward some views on this article, this article from the NBA culture and American politics; NBA culture and "hippie" culture; NBA culture inclusive and innovative features of the three aspects of Zhang Feng teacher questioned, hoping to achieve Academic contention and the purpose of mutual learning.

\section{The NBA Culture and American Politics}

The development of a nation's culture, in addition to being affected by a particular physical and geographical environment, as well as economic and external cultural constraints, the social and political ecology and structure of its impact is essential [1]. NBA culture and mainstream culture in the United States political ecology can not get rid of the US political environment on its impact in the NBA's development process of passive or active participation. "NBA culture and the mainstream American culture fit and departure" that "NBA culture is a different from the mainstream culture of the United States to depoliticize culture," "NBA culture is characterized by a significant departure from politics." NBA as a sports league (or business groups and cultural carriers), and other sports organizations, it should be a clear-cut opposition to politicization. But politics, like a nightmare, was accompanied by a process of major sporting events and events around the world. Historically, the Olympic Games had been resisted by political groups for many times and became a victim of political activity. The 1972 Munich Olympic tragedy in the history of the 20th Summer Olympic Games was the tragedy of two major political blocs, killing 11 Israeli athletes [2]. Whether it is the NBA or the Olympic Games, the dream away from politics, do not participate in politics has always been a mirage in general, is not. NBA as a commercial and cultural carrier, with McDonald's, Hollywood, as in the successful operation of the business at the same time, active or passive will be 
involved in political whirlpool. We would like to believe that the NBA is a clearcut opposition to political activity and that politics is far from sporting. So, it can be drawn NBA away from the political activities of the conclusion? Wishes and results can be consistent?

We may wish to first analysis of "NBA culture and the United States mainstream culture fit and departure" mentioned in the article Rodman's visit to North Korea's case. In the sensitive period of the Korean Peninsula, Rodman repeatedly visited the DPRK, each time by the North Korean leaders in highstandard reception, Rodman in North Korea in addition to basketball show games, to guide the Korean players for training, but also for the North Korean leadership People celebrate the birthday, in public, "affectionately" to the North Korean leaders singing birthday song, and many times in North Korea to mediate the release of detained US citizen Pei Junhao. Subsequently, the DPRK using the Korean Central News Agency, North Korea Central Television and other news media broadcast to the world access to the relevant news. Rodman in the December 19, 2013 third visit to the DPRK, after an interview with reporters, said, "I just want to start the basketball diplomacy." Although the US government has repeatedly stressed that Rodman's visit to the DPRK is a "personal act", but still let many people think of the last century, the United States to break the political stalemate "small ball turn big ball" table tennis diplomacy. So, "NBA players do not care about politics, their behaviour represents only their own, on behalf of basketball." This argument is objective? Whether Rodman himself admitted to the real purpose of visiting the DPRK "for the Korean people to NBA advanced technology and tactics and NBA culture." But his visit, far beyond the scope of sports exchanges, in fact, Rodman has been kidnapped by political, passive participation in political activities; another example: the 2012 US presidential election, former NBA president Stahn took the lead to provide Obama with a $\$ 5,000$ political donation to show political support for Obama and Democrats. That same year, the NBA's 74 athletes, coaches, team managers to Obama and Romney to provide political contributions, a total of 128,145 US dollars. Of the 74, Obama supported the President of the United States has 42 people, support Romney's 32 people. In fact, NBA interaction with the US president has never stopped, according to the Celtic team website news reports, as early as January 31, 1963, when the US President John F. Kennedy in the White House received The Celtics. In 1985, when Kareem Abdul-Jabbar led the Orlando Magic to the season, when President Reagan met the Orlando Magic at the White House, NBA champions have been visiting the White House since then, creating a culture of the NBA and White House politics Conventional activities. In summary, NBA is rooted in the US economy, culture, political ecology, can not be free from the political environment, the NBA and its culture strong, and its political and economic support are inseparable, the US political need to NBA and Its culture to shape its close to the public image, NBA alliance through the participation of US politicians to enhance the Union's influence in the international arena. If the "depoliticization is different from the NBA culture of the characteristics of the mainstream culture of the United States," it is only unrealistic dreams. 


\section{The NBA culture and "hippie" culture}

On the impact of any culture on modern politics, economy and culture, we must know the social background of the culture and the historical process of its cultural development. "Hippies" culture has been rooted in the process of budding, prospering and declining. In this process, "hippie culture has basically been absorbed, digested and lost the characteristics of anti-orthodox culture". As with other cultural phenomena, conflicts and collisions with mainstream culture are carried out. At the same time, they are compromised and compromised. Finally, they are integrated into the American multicultural system and become an inseparable part of American mainstream culture. The history of the "hippy" movement is the pursuit of "equality, democracy, freedom," the history of the "hippie" culture also reflects the mainstream culture of the United States "equality, democracy, freedom" core values.

The "hippie" culture was related to America's resistance to social conventions and politics in the 1960s. The "hippies" used communal movements and wandering lifestyles against Vietnam, racial discrimination, materialism, consumerism, and oppressive social and political atmosphere. In addition, the women's liberation movement, the rise of the civil rights movement for the "hippies" were anti-mainstream cultural movement foreshadowed. They believe that excessive material and consumption, creating the United States "ill-health society", but they use irrational means to confront with the mainstream American society, such as drug addiction, sexual liberation. At that time the mainstream culture of the United States refused to accept the "hippie" culture, try to exclude the "hippie" culture, the US government in order to limit the spread of the hippies movement in the country, strongly exaggerated the hippies movement can use shortcomings, labeled "drug", "social scum" symbol and label. In the face of the strong mainstream American culture, the "hippies" movement began to decline in the 1970s, but the "hippie" movement after a long struggle, but also led to the mainstream American society for some compromise, "hippie" The positive demands of the United States have been recognized by the mainstream culture, such as "respect for nature, return to nature" for the United States over the same period the environmental movement has played a positive role in promoting the "hippie" campaign shouted "to love, not war" War slogans, with the most simple language to express the anti-war, the desire to pursue peace, greatly promoted the anti-war movement, but also to the American public left a few distinctive impressions, this slogan even today is also significant significance. Even the long hair, jeans, and other dresses and costumes representing the "hippies" cultural symbols were widely recognized and accepted by people all over the world, regardless of their race or gender, such as the former president of the United States, known as the "cowboy president".

"Hippie" culture and American mainstream cultural exchange - conflict compromise - integration, embodies the cultural exchange and progress of the law. The "hippy" movement and the culture it produced had lost their social background and became a historical phenomenon and historical culture. In the confrontation with the powerful mainstream American culture, they also 
integrated into the mainstream American cultural system. Those who survived and were given The symbolic element of the "hippy" culture (such as long hair and jeans) has also become part of the multicultural system of the United States. It also carries the mainstream values of freedom, democracy, and equality in the United States. Those extreme irrational behaviour, drug use, sexual liberation, etc. have not been accepted by the mainstream culture. Therefore, the argument that the "hippies" culture "exists in parallel with the mainstream culture of the United States" is "a unique rebellious expression under the state legal system forms a cultural phenomenon" can not be established, and forgetting the irrational struggle means in the "hippie".

On the other hand, including the NBA official, want to create the NBA by the mainstream culture of cultural carrier, trying to dilute the "street culture" impression and influence, in the course of their business operation, to please the mainstream culture of the United States Class, and strive to make NBA culture with "modern", "fashion" symbol metaphor. For example: NBA has a number of teams to prohibit players "wearing headband", "wearing headband" this street clothing style, does not meet the "middle class" habits and aesthetic taste. In 2005 the NBA issued a "dress code", asked the coach to appear in front of the public with the business, no game players have to enter the competition venues are installed, prohibiting coaches and players without a game wearing a sleeveless shirt, T-shirt, T Blood shirt, shorts into the venue and so on. NBA former president David Stern said in an interview with ESPN, "no competition must wear suits and dress code is to create a good NBA image of the Union"

Based on a review of the "hippie" culture and the fact that the NBA is striving to represent the middle class of the American mainstream culture, we see the NBA's global popularity as being comparable to that of the "hippie" culture the prevalence is too reluctant. NBA spread in many countries around the world, in the cultural level thanks to the NBA with the media to show the world the results of the mainstream American culture. Some players with "hippie" elements of personal behaviour, such as tattoos, maverick eccentric shape, but the NBA for commercial operation to win the eye of the tool is the NBA business operation of the "premeditated" Bale. Therefore, the "hippies advocating the spirit of freedom is the NBA swept the world's important reasons," the argument biased and the mainstream culture of the United States "respect for the spirit of freedom." Therefore, we prefer to believe that the mainstream culture of the United States and multicultural inclusive atmosphere together to promote the NBA and its culture to the world.

\section{The inclusive and innovative features of NBA culture}

The United States is an innovative country, with the modernist concept of consciousness, the United States not only in innovation and industrial and economic, its cultural innovation is also true, American society presents the cultural industry and cultural phenomenon of "flourishing" scene, precisely because this immigrant country provides an environment for cultural innovation. 
NBA culture as part of the mainstream culture of the United States, and with the advancement of the globalization process, becomes the sports economy and cultural industry leader. Unimaginable, in advocating innovation in the United States, NBA such a highly respected cultural carrier, its culture is a conservative culture. "NBA culture and the mainstream American culture fit and departure" that "NBA culture does not accept foreign culture, as a special case of sports culture seems conservative." NBA really is not willing to accept other cultures?

This is not the case and we can find from the NBA's growth NBA culture is an open culture, rather than a conservative culture. NBA as part of the culture of the system, NBA rules of the game continue to be modified, to encourage the attack, increase the game watch, NBA games are not bound by the traditional rules of the basketball, expanding the three seconds zone. NBA in accordance with the needs of the development of basketball technology, regional defense has never allowed the introduction of regional defense, in order to maintain the smooth game, to enhance the authority of the referee in the law enforcement process, NBA 20062007 season, "zero tolerance" referee enforcement system . In the material culture, the NBA on a regular basis, such as the replacement of jerseys, to protect the competition venues, technical support facilities continue to update, upgrade and so on. NBA culture, the use of commercial means of operation, do everything possible to meet the needs of consumers, the NBA and its culture continue to innovate, reflecting the distinctive characteristics of the times. NBA itself not only continues to innovate and improve, but also attach importance to the absorption of foreign culture to NBA players tattoo, for example, NBA players have Chinese tattoo. Such as: Iverson in the neck tattoo content for the "loyalty", nicknamed the bird's Anderson to the Chinese character "good" pattern in their own arm.

In addition, Zhang Feng, the teacher that "the NBA never copied the NBA anywhere else in the world, nor to any geographical instill NBA cultural values," to illustrate the NBA is different from other cultures with expansion of the United States. We believe that NBA is a strong sports culture and it also has expansion, with input to the output of the cultural values of the essential attributes. In 2004 China's first contractor NBA China, NBA League stadium requirements in accordance with the NBA model decoration, also requires from the United States to bring cheerleaders, live music style, promotional materials must be held in the United States, and even asked to provide to the team Mascot VIP room, the game with the floor from the United States air, strongly compressed to be input to the cultural expression of space. Then the NBA never copied the NBA anywhere else in the world, nor to any regional instill NBA cultural values, "the argument can not be established.

\section{Conclusion}

NBA culture is part of the mainstream culture of the United States, which is rooted in American politics, economy and culture. It has not and will not deviate from the mainstream culture of the United States system, NBA culture has become a typical representative of the mainstream culture of the United States, 
opened the US cultural globalization expansion journey. In this process, even if the NBA has the desire to politicize, but it is still active or passive political coerced. In the context of globalization, the NBA and its culture continue to selfimprovement and absorb different regional cultures, hoping to get the most cultural identity in order to win the economic interests. Through the studying of NBA culture and the mainstream culture of the United States, including the NBA culture, including the essence of the United States mainstream culture, has practical significance on blindly superstition NBA and its culture, especially trying to make CBA culture NBA of our business and sports at the moment.

\section{References}

[1] Michael H. Hunter. Ideology and American Foreign Policy. Beijing: World Knowledge Publishing House. pp.68-70, 2011

[2] Ren Hai. Olympic Games. Beijing: People's Sports Publishing House. pp. 8791, 2013

[3] Fang Xiao. Rodman returns to North Korea to engage in "basketball diplomacy", Oriental Morning Post, pp. 18- 20, 2012

[4] Wang Enming, American Anti-Orthodox Movement: Research on Hippies Culture. Beijing: Peking University Press, pp.58- 61, 2011

[5] Xia Xuehua. Hippies: the mainstream of the United States rebellious generation. Shanghai: Shanghai Dictionary Publishing House, pp.85-87, 2014 